\title{
Health Equity Insights from Machine Learning Models
}

J Gen Intern Med 36(8):2475

DOI: $10.1007 / \mathrm{s} 11606-021-06908-0$

(c) Society of General Internal Medicine 2021

$\mathrm{T}$ he Behavioral Risk Factor Surveillance System (BRFSS) is the United States' (US) largest health survey administered by telephone, and a valuable source of data on social determinants of health (SDH). ${ }^{1}$ Clark and colleagues apply machine learning methods to the BRFSS data to identify SDH associated with inequities in self-rated health. ${ }^{2}$ The BRFSS technical documentation recommends applying survey weights to generate estimates representative of the US population. ${ }^{3}$ Clark and colleagues use weighted logistic regression to predict the odds of excellent or very good health, but do not use survey weights in their descriptive analysis of the sample. Whereas the results section refers to "the weighted prevalence of self-rated health and other study covariates ... in Table 1," the footnote to Table 1 states, "Percentages [are] unweighted and represent the characteristics of survey respondents but not population estimates."

The unweighted percentages in Table 1 reveal a sample that is biased on several characteristics compared to the population it is intended to represent. Comparing Table 1 to the CDC's interactive tool for analyzing 2017 BRFSS data (while applying survey weights), ${ }^{4}$ the unweighted proportion of respondents identifying as non-Hispanic White is $83.3 \%$, vs. a population proportion of $72.3 \%$. Furthermore, $37.6 \%$ of sample respondents vs. $26.0 \%$ of the population have completed a college degree. Therefore, it is important to accurately label the descriptive analysis as unweighted, and to acknowledge limitations that result from the BRFSS enrolling a sample that over-represents non-Hispanic White and highly educated participants. Surveys which are administered by other modes may achieve better representation of the US population and may

Received March 1, 2021

Accepted April 30, 2021

Published online May 19, 2021

reveal different conclusions about SDH affecting health equity.

Dmitry Tumin, $P h D^{1}$

${ }^{1}$ Department of Pediatrics, Brody School of Medicine at East Carolina University,

Greenville, NC, USA

Corresponding Author: Dmitry Tumin, PhD; Department of Pediatrics, Brody School of Medicine at East Carolina University, Greenville, NC, USA (e-mail: tumind18@ecu.edu).

\section{Declarations:}

Conflict of Interest: The author declares that he does not have a conflict of interest.

\section{REFERENCES}

1. Centers for Disease Control and Prevention (CDC). Behavioral Risk Factor Surveillance System. Available at: https://www.cdc.gov/brfss/index.html. Accessed 1 March 2021.

2. Clark CR, Ommerborn MJ, Moran K, Brooks K, Haas J, Bates DW, Wright A. Predicting Self-Rated Health Across the Life Course: Health Equity Insights from Machine Learning Models. J Gen Intern Med. 2021 Epub ahead of print.

3. CDC. Overview: BRFSS 2017. Available at https://www.cdc.gov/brfss/ annual_data/2017/pdf/overview-2017-508.pdf. Accessed 1 March 2021.

4. CDC. BRFSS Prevalence \& Trends Data. https://www.cdc.gov/brfss/ brfssprevalence/. Accessed 28 February 2021.

Publisher's Note: Springer Nature remains neutral with regard to jurisdictional claims in published maps and institutional affiliations. 